\title{
Maternal Plasma Hepatocyte Growth Factor Concen- trations in Women Who Subsequently Developed Preeclampsia
}

Shin Young Kim¹, So Yeon Park', Mi Jin Kim¹, Moon Young Kim², Kyu Hong Choi ${ }^{2}$, Dong Wook Kwak², Yoo Jung Han ${ }^{2}$ and Hyun Mee Ryu ${ }^{1,2 *}$

'Laboratory of Medical Genetics, Cheil General Hospital and Women's Healthcare Center, Seoul, Korea

${ }^{2}$ Department of Obstetrics and Gynecology, Cheil General Hospital and Women's Healthcare Center, Kwandong University College of Medicine, Seoul, Korea

\begin{abstract}
Purpose: The aim of this nested case-control study was to investigate the association between hepatocyte growth factor (HGF) concentrations in maternal plasma and the risk of developing preeclampsia.

Materials and Methods: Plasma HGF concentration were measured in 52 women who subsequently developed preeclampsia and 104 normal pregnant women at the time of genetic amniocentesis (15-20 weeks) by enzyme-linked immunosorbent assay.

Results: Maternal plasma HGF concentrations were significantly higher in women with subsequent preeclampsia (median: $737.8 \mathrm{ng} / \mathrm{mL}$ vs. $670.4 \mathrm{ng} / \mathrm{mL}, P=0.003$ ) than in normal controls. However, HGF concentrations were not significantly different between subgroups by preeclamptic complications. After adjusting for potential confounding factors, women with HGF concentrations $\geq 702.5 \mathrm{ng} / \mathrm{mL}$ had a 3.2-fold increased risk (95\% Cl 2.7-5.4, $P<0.001)$ of subsequent development of preeclampsia compared with women with HGF concentrations $<702.5 \mathrm{ng} / \mathrm{mL}$.

Conclusion: Elevated maternal plasma HGF concentrations in the early second-trimester are associated with an increased risk of developing preeclampsia.
\end{abstract}

Key words: Plasma, Hepatocyte growth factor, Risk factor, Subsequent preeclampsia

\section{Introduction}

Preeclampsia, a pregnancy-related syndrome, is characterized by maternal hypertension and proteinuria after 20 weeks of gestation, affecting approximately $5-10 \%$ of all pregnancies." This syndrome, a leading cause of maternal and perinatal morbidity and mortality, occurs only in the presence of a placenta and remits dramatically after the placenta has been delivered. ${ }^{2)}$

Despite extensive research, the pathophysiology of this condition remains unclear. Accumulating evidence, however, indicates that failure of the cytotrophoblast invasion of maternal uterine spiral arteries plays a central role. ${ }^{3,4)}$ Consequently, reduction of uteroplacental blood perfusion by shallow implantation results in local placental hypoxia. ${ }^{5)}$ Chronic hypoxia

Received: 20 Nov 2012, Revised: 14 Dec 2012, Accepted: 18 Dec 2012, Published: 31 Dec 2012

${ }^{*}$ Corresponding author: Hyun Mee Ryu, MD, PhD

Department of Obstetrics and Gynecology, Cheil General Hospital and Women's Healthcare Center, Kwandong University College of Medicine, 1-19 Mukjeong-dong, Jung-gu, Seoul 100-380, Korea.

Tel: +82-2-2000-7683, Fax: +82-2-2278-4574, E-mail: hmryu@yahoo.com

(c) This is an open-access article distributed under the terms of the Creative Commons Attribution Non-Commercial License (http://creativecommons.org/licenses/by-nc/3.0/) which permits unrestricted non-commercial use, distribution, and reproduction in any medium, provided the original work is properly cited.

(c) Copyright 2012 by the Korean Society of Medical Genetics 
or alternate periods of hypoxia/re-oxygenation within the intervillous space are expected to trigger tissue oxidative stress and increase placental apoptosis and necrosis. ${ }^{6,7)}$ A hypoxic/ ischemic placenta may then release soluble factors, cytokines, and trophoblastic debris into the maternal circulation eventually causing systemic endothelial damage and dysfunction, which leads to the main clinical symptoms of preeclampsia. ${ }^{8-10)}$

Hepatocyte growth factor (HGF), a pleiotropic cytokine, regulates cell growth, differentiation, and morphogenesis in many different cell types and tissues. It is also a potent angiogenic factor that stimulates the proliferation and migration of endothelial and smooth muscle cells. ${ }^{11,12)}$ In the human placenta, HGF is expressed in the placental villous core and acts in a paracrine manner on trophoblasts expressing the HGF receptor (HGFR, also known as c-Met). ${ }^{13)}$ HGF knockout mutations in mice result in embryonic death in utero due to placental insufficiency. ${ }^{14)}$ HGF has been postulated to play an essential role in placental development. We hypothesize that plasma HGF concentrations are aberrant in women who subsequently develop preeclampsia prior to clinical manifestation of the symptoms of preeclampsia. In this nested case-control study, we investigated the relationship of the early second-trimester plasma HGF concentrations and the risk of developing preeclampsia.

\section{Materials and Methods}

All subjects were recruited prospectively from the Obstetrics and Gynecology Department at Cheil General Hospital in Seoul, Korea between October 2001 and June 2004. Maternal venous blood samples were collected from a cohort of 3,000 consenting women at the time of genetic amniocentesis and diagnosis of preeclampsia. Blood samples and clinical data were collected with the approval of the Ethics Committee at Cheil General Hospital (CGH-IRB-2010-35), and a written informed consent was obtained from all participants. We retrospectively reviewed the medical records of 3,000 recruited pregnant women. A nested case-control study was conducted in 52 women with subsequent preeclampsia and 104 normal pregnant women at the time of genetic amniocentesis (15-20 weeks). At the time of sampling, women with subsequent preeclampsia included in the study were clinically healthy and showed no signs of preeclampsia or other pregnancy complications. Exclusion criteria included prior preeclampsia, spontaneous abortion, intrauterine fetal death, fetal chromosomal or congenital abnormalities, alcohol consumption, smoking, and preexisting medical conditions such as diabetes, chronic hypertension, autoimmune disease, or renal disease.

Preeclampsia was sub-classified as mild preeclampsia and severe preeclampsia according to disease severity, term preeclampsia ( $\geq 37$ weeks) and preterm preeclampsia ( $<37$ weeks) according to delivery week, and preeclampsia who delivered an appropriate for gestational age (AGA) neonate and preeclampsia who delivered a small for gestational age (SGA) neonate according to birth weight of a neonate.

Preeclampsia was diagnosed as hypertension (systolic blood pressure $\geq 140 \mathrm{mmHg}$ and/or diastolic blood pressure $\geq 90$ $\mathrm{mmHg}$ ) and proteinuria ( $\geq 300 \mathrm{mg}$ in a $24 \mathrm{~h}$ urine collection and/ or $\geq 1+$ on dipstick testing) after 20 weeks of gestation. ${ }^{15)}$ Severe preeclampsia was diagnosed as diastolic blood pressure $\geq 110$ $\mathrm{mmHg}$; severe proteinuria (urinary protein excretion $\geq 5 \mathrm{~g}$ per $24 \mathrm{hr}$ and / or $\geq 3+$ on dipstick testing); evidence of pulmonary edema; seizures; oliguria ( $<500 \mathrm{~mL} /$ day); thrombocytopenia (platelet count $<100,000 / \mathrm{mL}$ ); and severe central nervous system symptoms such as altered mental status, headaches, blurred vision, or blindness. ${ }^{15)}$ SGA and AGA were defined by a birth weight below the $10^{\text {th }}$ percentile and a birth weight from the $10^{\text {th }}$ to $90^{\text {th }}$ percentile for gestational age at birth, respectively, according to the national birth weight distribution of the Korean population. ${ }^{16)}$

A patient was considered to have a normal pregnancy if she met the following criteria: 1) singleton gestation; 2) no medical, obstetrical or surgical complications; 3 ) absence of labor at the time of venipuncture; and 4) delivery of a normal term infant ( $\geq 37$ weeks) whose birth weight was between the $10^{\text {th }}$ and $90^{\text {th }}$ percentile for gestational age.

Maternal peripheral blood was collected in EDTA-containing tubes and was centrifuged at 2,500g for $10 \mathrm{~min}$ within $24 \mathrm{~h}$ after sampling. The supernatant plasma was transferred into a $1.5 \mathrm{ml}$ sterile tube, and aliquots of plasma were stored at $-80^{\circ} \mathrm{C}$ until use. Plasma HGF concentrations were measured by ELISA kit (Invitrogen Corporation, Camarillo, CA, USA). The inter- and intraassay coefficients of variation were $7.2 \%$ and $5.4 \%$, respectively.

Statistical analysis was performed using the Statistical Package for Social Sciences version 12.0 (SPSS, Chicago, IL, USA). The clinical data were compared by the Student's t test for continuous variables and by the $x^{2}$ test for categorical variables. A comparison of HGF concentration between the two groups was performed using the Mann-Whitney U test.

Receiver operating characteristic (ROC) analysis was performed to assess the best cut-off value and discriminating capacity of the HGF concentration in the second-trimester plasma for predicting women who subsequently developed preeclampsia. Logistic 
regression analysis was used to adjust for the effects of covariates (maternal age, body mass index, nulliparity and gestational age at sampling) and identify independent relationships with results reported as adjusted odds ratios (OR) with 95\% confidence intervals (Cl). A $P$ value of $<0.05$ was considered statistically significant.

\section{Results}

The clinical characteristics of the study population are shown in Table 1. There were no significant differences in maternal age and gestational age at sampling between women with subsequent preeclampsia and normal controls $(P>0.05)$. However, nulliparous women and body mass index (BMI) were higher in women with subsequent preeclampsia compared to the controls $(P<0.05)$. At the time of sampling, blood pressures and proteinuria were not significantly different between women with subsequent preeclampsia and controls $(P>0.05)$. The gestational age at delivery was earlier and the fetal birth weights were lower in women with subsequent preeclampsia compared to the controls $(P<0.001)$.

The maternal plasma HGF concentrations in the second-

Table 1. Clinical Characteristics of the Study Population

\begin{tabular}{|c|c|c|c|}
\hline & $\begin{array}{l}\text { Controls } \\
(n=104)\end{array}$ & $\begin{array}{l}\text { Women with } \\
\text { subsequent } \\
\text { preeclampsia } \\
(\mathrm{n}=52)\end{array}$ & $P$ \\
\hline \multicolumn{4}{|l|}{ Characteristics at sampling } \\
\hline Maternal age (y) & $33.8 \pm 3.9$ & $33.0 \pm 3.5$ & 0.163 \\
\hline Nullipara & $52(50.0 \%)$ & $36(69.2 \%)$ & 0.012 \\
\hline $\mathrm{BMI}\left(\mathrm{kg} / \mathrm{m}^{2}\right)$ & $21.1 \pm 2.5$ & $22.7 \pm 3.0$ & 0.002 \\
\hline Gestational age (weeks) & $16.8 \pm 1.3$ & $17.0 \pm 1.3$ & 0.136 \\
\hline $\mathrm{SBP}(\mathrm{mmHg})$ & $115.3 \pm 10.7$ & $118.5 \pm 13.0$ & 0.446 \\
\hline $\mathrm{DBP}(\mathrm{mmHg})$ & $68.6 \pm 6.4$ & $70.0 \pm 5.6$ & 0.381 \\
\hline Proteinuria (dipstick) & Negative & Negative & - \\
\hline \multicolumn{4}{|c|}{ Characteristics at presentation } \\
\hline $\mathrm{SBP}(\mathrm{mmHg})$ & - & $157.7 \pm 13.0$ & $<0.001^{\mathrm{a}}$ \\
\hline $\mathrm{DBP}(\mathrm{mmHg})$ & - & $100.2 \pm 9.5$ & $<0.001^{\mathrm{a}}$ \\
\hline Proteinuria (dipstick) & - & $2.5 \pm 0.9$ & $<0.001^{b}$ \\
\hline \multicolumn{4}{|l|}{ Characteristics at delivery } \\
\hline Gestational age (weeks) & $39.2 \pm 1.2$ & $36.0 \pm 3.6$ & $<0.001$ \\
\hline Birth weight (g) & $3378.8 \pm 361.1$ & $2456.9 \pm 403.8$ & $<0.001$ \\
\hline
\end{tabular}

Data are presented as mean $\pm S D$ or number (percentage).

BMI, body mass index; SBP, systolic blood pressure; DBP, diastolic blood pressure.

${ }^{a}$ Blood pressure at sampling vs. at presentation in women with subsequent preeclampsia

${ }^{0}$ Proteinuria at sampling vs. at presentation in women with subsequent preeclampsia trimester (15-20 weeks) were higher in women with subsequent preeclampsia than those in normal controls $(737.8 \mathrm{ng} / \mathrm{mL}$ (range: $495.8-1508.1 \mathrm{ng} / \mathrm{mL}$ ) vs. $670.4 \mathrm{ng} / \mathrm{mL}$ (range: 387.6 $1276.0 \mathrm{ng} / \mathrm{mL}$ ), $P=0.003$ ) (Fig. 1). When women with subsequent preeclampsia were sub-classified according to complications, the maternal plasma concentrations of HGF were not significantly different between subgroups(Table 2).

We analyzed the change of HGF concentrations in each group according to gestational age (Fig. 2). The concentrations of HGF was positively correlated with gestational age for control groups $(r=0.256, P=0.009)$. However, there is no correlation

Table 2. Maternal Plasma HGF Concentrations in Subgroups of Women who Subsequently Developed Preeclampsia

\begin{tabular}{lcc}
\hline & $\begin{array}{c}2^{\text {nd }} \text { trimester HGF concentration } \\
(\mathrm{ng} / \mathrm{mL})\end{array}$ & $P$ \\
\hline $\begin{array}{l}\text { Disease severity } \\
\text { Mild }\end{array}$ & $732.8(533.6-1508.1)(\mathrm{n}=15)$ & 0.592 \\
$\quad$ Severe & $742.8(495.8-1279.4)(n=37)$ & \\
Gestational week at delivery & $762.5(495.8-1508.1)(n=27)$ & 0.821 \\
$\quad$ Term & $719.4(501.0-1318.1)(n=25)$ & \\
Preterm & & \\
Birth weight at delivery & $749.4(531.7-1279.4)(n=32)$ & 0.908 \\
AGA & $718.1(495.8-1508.1)(n=20)$ & \\
SGA & & \\
\hline
\end{tabular}

Data are presented as median (range).

AGA: appropriate for gestational age; SGA: small for gestational age.

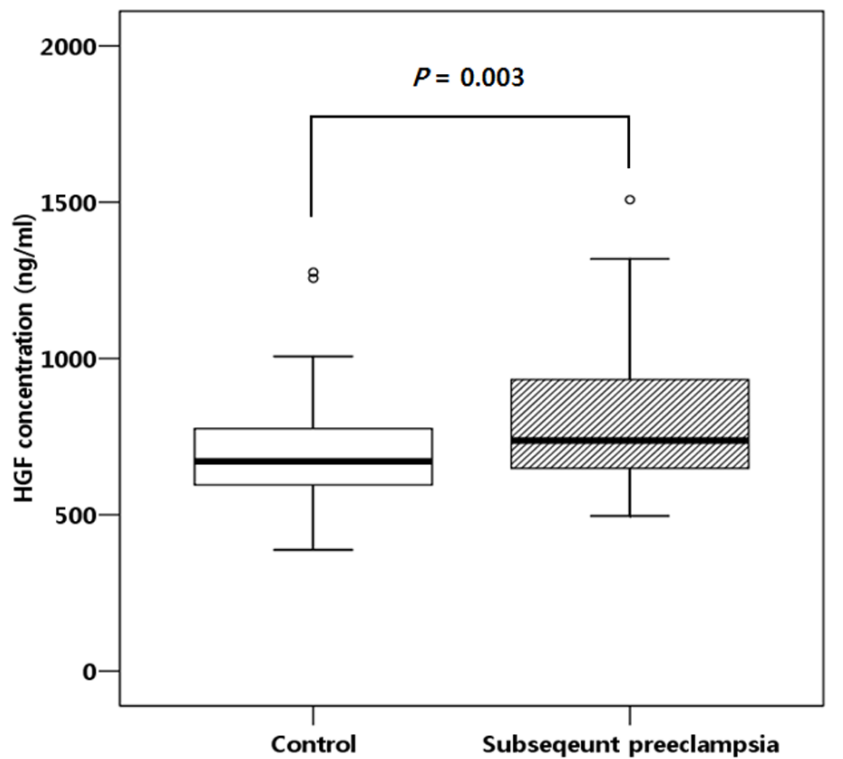

Fig. 1. Box plots of the HGF concentrations in control and subsequent preeclampsia groups in the second-trimester. The upper and lower limits of the boxes represent the $75^{\text {th }}$ and $25^{\text {th }}$ percentiles, respectively. The upper and lower whiskers represent the $90^{\text {th }}$ and $10^{\text {th }}$ percentiles, respectively. The median is indicated by the line in each box. Outliers are indicated by circles. 
between gestational age and $\mathrm{HGF}$ concentration in women with subsequent preeclampsia $(r=-0.051, P=0.726)$.

The maternal plasma HGF concentration with the best cut-off value of $702.5 \mathrm{ng} / \mathrm{mL}$ had a specificity of $72 \%$ and a sensitivity of 70\% (area under the curve [95\% CI]: 0.738 [0.643-0.833], $P=$ 0.005 ). The logistic regression analysis revealed a significant association between second-trimester HGF concentrations and the risk of developing preeclampsia in the unadjusted and adjusted analyses. In the unadjusted analysis, second-trimester HGF concentration of higher than $702.5 \mathrm{ng} / \mathrm{mL}$ was associated with a 2.5fold increase risk of subsequent development of preeclampsia (95\% $\mathrm{Cl} 1.3-4.9, P=0.009)$. After adjusting for maternal age, nulliparity, BMI, gestational age at sampling and gestational age at delivery, HGF in the analysis increased the OR to $3.2(95 \% \mathrm{Cl} 2.7-$ $5.4, P<0.001$ ) for women with subsequent preeclampsia.

\section{Discussion}

The present study shows that the second-trimester plasma HGF concentrations are higher in women who subsequently developed preeclampsia compared to the normal pregnant women. These elevations are observed at less than 20 weeks of gestation, indicating that elevations in maternal plasma HGF may be useful in identifying women at higher risk for subsequent development of preeclampsia early in gestation.

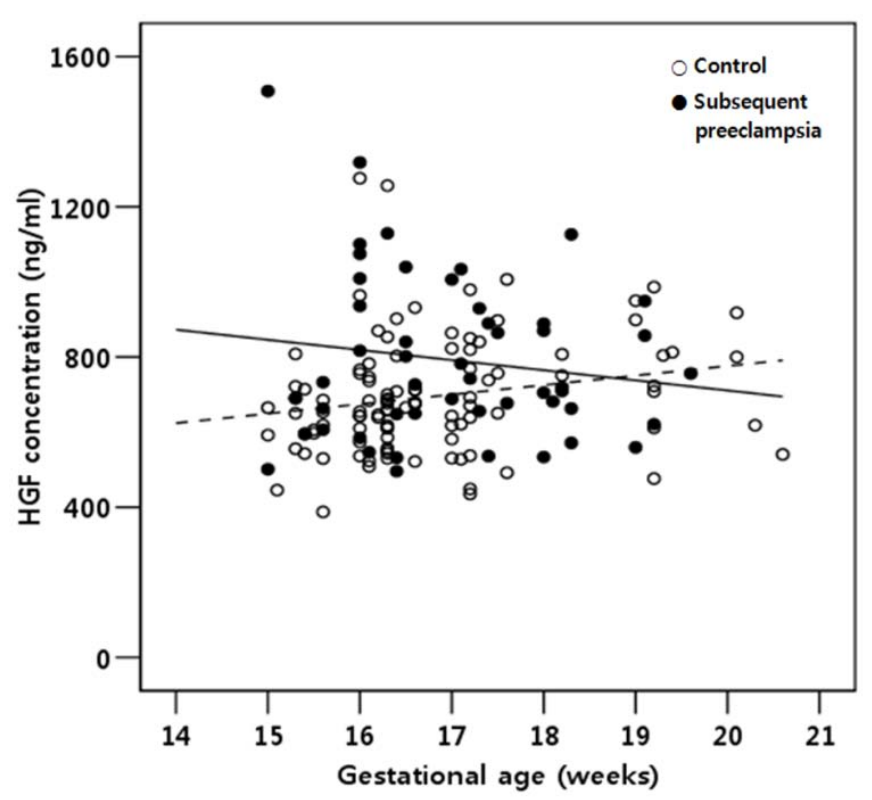

Fig. 2. Correlation between maternal plasma HGF concentration and gestational age in control and subsequent preeclampsia groups. The solid and dashed lines indicate the regression lines for the subsequent preeclampsia and control groups, respectively.
Our results are in line with previous study of Clark et al., ${ }^{17)}$ who found that HGF levels start to increase significantly with increasing gestational age from the second half of gestation onwards. They demonstrated that concentrations of circulating HGF in women with intrauterine growth restriction increase gradually during pregnancy and then drop significantly postpartum. In contrast, Tjoa et al. reported that the second-trimester plasma HGF concentrations in preeclamptic patients were not significantly different from normal pregnant women, while those in women with SGA fetuses were significantly elevated. ${ }^{18)}$ The reasons for this discrepancy are not clear. However, Tjoa et al. used an ELISA kit for HGF from a different manufacturer for use with pregnancy samples. ${ }^{18)}$ Furthermore, it may be based on the small sample size and differences in the populations studied. Further investigations are needed to confirm these findings and to identify the pathophysiological mechanism underlying the alteration of plasma HGFin preeclampsia.

The HGF/c-Met singling pathway plays an important role not only in embryogenesis and development but also in angiogenesis. ${ }^{19-21)}$ Function of HGF is mediated by the tyrosine kinase receptor, c-Met. Evidences have revealed that the integral c-Met can be released from the endothelial cell membrane by proteolysis to form a soluble, truncated protein (sMet), which is able to bind HGF and disrupt HGF/c-Met signaling. ${ }^{22)}$ At present, it remains unclear whether there exist interactions between HGF and sMet, and we do not know the cause-effect relationship between the circulating sMet and endothelial dysfunction in the occurrence of preeclampsia. Thus, further studies are needed to determine the significance of this substance in the pathophysiology of preeclampsia.

Three facts regarding the placenta in preeclampsia are known: an association with large placentas (excessive trophoblast), a tendency for superficial implantation, and inappropriate trophoblastic immaturity, as assessed by ultrastructural and biochemical criteria. ${ }^{23-25)}$ A unitary hypothesis is that preeclampsia is related to a maturation defect leading to excessive accumulation of inappropriately immature intermediate trophoblast in the placental implantation site. Redline et al. reported that preeclampsia has been associated with an immature hyperproliferative trophoblast in response to reduced uteroplacental flow. ${ }^{26)} \mathrm{HGF}$ is known to be a mesenchymal effector for proliferation, differentiation, and function of the uterine epithelial cells. ${ }^{27,28)}$ Possibly, the excessive proliferation of cytotrophoblast cells in preeclamptic pregnancies may be accompanied by or preceded by increased HGF production. However, it remains unclear why HGF concentrations were altered in preeclamptic pregnancies. Maternal serum HGF 
concentrations have been reported to be increased in women with HELLP syndrome during the third-trimester. ${ }^{29)}$ Although part of the HGF originates from the placenta ${ }_{1}{ }^{30}$ other organs such as the maternal liver and kidney may equally contribute to the levels of circulating $\mathrm{HGF}^{3{ }^{31)}}$ It is therefore unlikely that the elevated HGF concentrations found in women with subsequent preeclampsia can be attributed solely to increased placental production. Change of circulating HGF in preeclamptic pregnancies might reflect the much early malfunctions in these maternal organs.

The limitations of this study are that we only included patients from a Korea population. In addition, the number of preeclamptic patients in the second-trimester of pregnancy was relatively small (52 cases, respectively), although it reflects the real prevalence of the early form of the disease, which is $\approx 0.8 \%{ }^{32)}$ Finally, it may be considered that prediction for preeclampsia at 15-20 weeks of gestation is relatively late. Recent studies are focusing in predicting preeclampsia with use of uterine artery Doppler and other biochemical markers in the first-trimester. ${ }^{33-35)}$ Thus, further large-scale, prospective, longitudinal studies are necessary to confirm these results and to assess the usefulness of HGF as an important risk factor for the development of preeclampsia.

In conclusion, we found increased maternal plasma HGF concentrations in women who subsequently developed preeclampsia. Moreover, alterations of the second-trimester HGF concentrations were significantly associated with an increased risk of subsequent development of preeclampsia and could offer insight into disease pathogenesis and the potential for early prediction.

\section{Acknowledgements}

This research was supported by Basic Science Research Program through the National Research Foundation of Korea (NRF) funded by the Ministry of Education, Science and Technology (2010-0006921).

\section{References}

1. Sibai B, Dekker G, Kupferminc M. Pre-eclampsia. Lancet $2005 ; 365$ : 785-99.

2. Page EW. The relation between hydatid moles, relative ischemia of the gravid uterus, and the placental origin of eclampsia. Am J Obstet Gynecol 1939;37:291-3.

3. Pijnenborg R, Anthony J, Davey DA, Rees A, Tiltman A, Vercruysse
$L_{1}$ et al. Placental bed spiral arteries in the hypertensive disorders of pregnancy. Br J Obstet Gynaecol 1991;98:648-55.

4. Silasi M, Cohen B, Karumanchi SA, Rana S. Abnormal placentation, angiogenic factors, and the pathogenesis of preeclampsia. Obstet Gynecol Clin North Am 2010;37:239-53.

5. Caniggia I, Winter J, Lye SJ, Post M. Oxygen and placental development during the first trimester: implications for the pathophysiology of preeclampsia. Placenta 2000;21 Suppl A:S25-30.

6. Hung TH, Skepper JN, Charnock-Jones DS, Burton GJ. Hypoxiareoxygenation: a potent inducer of apoptotic changes in the human placenta and possible etiological factor in preeclampsia. Circ Res 2002;90:1274-81.

7. Soleymanlou N, Jurisica I, Nevo O, letta F, Zhang X, Zamudio S, et al. Molecular evidence of placental hypoxia in preeclampsia. J Clin Endocrinol Metab 2005;90:4299-308.

8. Roberts JM, Hubel CA. Is oxidative stress the link in the two-stage model of preeclampsia? Lancet 1999;354:788-9.

9. Kim SY, Park SY, Kim JW, Choi JS, Ahn HK, Han JY, et al. Reduced number of endothelial progenitor colony-forming units in patients with preeclampsia. J Genet Med 2010;7:138-44.

10. Kim SY and Ryu HM. Genetics of pre-eclampsia. J Genet Med 2011; 8:17-27.

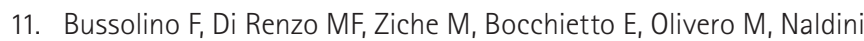
$L$, et al. Hepatocyte growth factor is a potent angiogenic factor which stimulates endothelial cell motility and growth. J Cell Biol 1992;119:629-41.

12. Walter JJ, Sane DC. Angiostatin binds to smooth muscle cells in the coronary artery and inhibits smooth muscle cell proliferation and migration in vitro. Arterioscler Thromb Vasc Biol 1999;19:2041-8.

13. Kauma SW, Bae-Jump V, Walsh SW. Hepatocyte growth factor stimulates trophoblast invasion: a potential mechanism for abnormal placentation in preeclampsia. J Clin Endocrinol Metab 1999;84:4092-6.

14. Uehara Y, Minowa O, Mori C, Shiota K, Kuno J, Noda T, et al. Placental defect and embryonic lethality in mice lacking hepatocyte growth factor/scatter factor. Nature 1995;373:702-5.

15. ACOG practice bulletin. Diagnosis and management of preeclampsia and eclampsia. Number 33, January 2002. American College of Obstetricians and Gynecologists. Int J Gynaecol Obstet 2002;77:67-75.

16. Park HM. Korean Society of Obstetrics and Gynecology: Obstetrics. 4th ed. Seoul: KoonJa, 2007;626.

17. Clark DE, Smith SK, Sharkey AM, Sowter HM, Charnock-Jones DS. Hepatocyte growth factor/scatter factor and its receptor c-met: localisation and expression in the human placenta throughout pregnancy. J Endocrinol 1996;151:459-67.

18. Tjoa ML, Mulders MA, van Vugt JM, Blankenstein MA, Oudejans $C B$, van Wijk IJ. Plasma hepatocyte growth factor as a marker for small-for-gestational age fetuses. Eur J Obstet Gynecol Reprod Biol 2003;110:20-5. 
19. Birchmeier C, Birchmeier W, Gherardi E, Vande Woude GF. Met, metastasis, motility and more. Nat Rev Mol Cell Biol 2003;4:915-25.

20. Zhang YW, Su Y, Volpert OV, Vande Woude GF. Hepatocyte growth factor/scatter factor mediates angiogenesis through positive VEGF and negative thrombospondin 1 regulation. Proc Natl Acad Sci U S A 2003;100:12718-23.

21. Ding S, Merkulova-Rainon T, Han ZC, Tobelem G. HGF receptor upregulation contributes to the angiogenic phenotype of human endothelial cells and promotes angiogenesis in vitro. Blood 2003;101: 4816-22.

22. Wajih N, Walter J, Sane DC. Vascular origin of a soluble truncated form of the hepatocyte growth factor receptor (c-met). Circ Res 2002; 90:46-52.

23. PritchardJA, MacDonald PC. Hypertensive disorders of pregnancy. In: Pritchard JA, MacDonald PC, eds. Williams' Obstetrics. 16th ed. New York: NY Appleton-Century Crofts, 1980;665-700.

24. Khong TY, De Wolf F, Robertson WB, Brosens I. Inadequate maternal vascular response to placentation in pregnancies complicated by pre-eclampsia and by small-for-gestational age infants. Br J Obstet Gynaecol 1986;93:1049-59.

25. Arkwright PD, Rademacher TW, Dwek RA, Redman CW. Pre-eclampsia is associated with an increase in trophoblast glycogen content and glycogen synthase activity, similar to that found in hydatidiform moles. J Clin Invest 1993;91:2744-53.

26. Redline RW, Patterson P. Pre-eclampsia is associated with an excess of proliferative immature intermediate trophoblast. Hum Pathol 1995;26:594-600.
27. Sugawara J, Fukaya T, Murakami T, Yoshida H, Yajima A. Hepatocyte growth factor stimulated proliferation, migration, and lumen formation of human endometrial epithelial cells in vitro. Biol Reprod 1997; 57:936-42.

28. Wimsatt WA. New histological observations on the placenta of the sheep. Am J Anat 1950;87:391-457.

29. lioka H. Clinical use of human hepatocyte growth factor in the early detection of HELLP syndrome. Gynecol Obstet Invest 1996;41:103-5.

30. Horibe N, Okamoto T, Itakura A, Nakanishi T, Suzuki T, Kazeto S, et al. Levels of hepatocyte growth factor in maternal serum and amniotic fluid. Am J Obstet Gynecol 1995;173:937-42.

31. Ho RT, Liew CT, Lai KN. The expression of hepatocyte growth factor (HGF) and interleukin 6 (IL-6) in damaged human liver and kidney tissues. Hepatogastroenterology 1999;46:1904-9.

32. Espinoza J, Romero R, Nien JK, Gomez R, Kusanovic JP, Gonçalves LF, et al. Identification of patients at risk for early onset and/or severe preeclampsia with the use of uterine artery Doppler velocimetry and placental growth factor. Am J Obstet Gynecol 2007;196:326.e1-13.

33. Mikat B, Zeller A, Scherag A, Drommelschmidt K, Kimmig R, Schmidt $\mathrm{M} . \beta \mathrm{hCG}$ and PAPP-A in first trimester: predictive factors for preeclampsia? Hypertens Pregnancy 2012;31:261-7.

34. Audibert F, Boucoiran I, An N, Aleksandrov N, Delvin E, Bujold E, et al. Screening for preeclampsia using first-trimester serum markers and uterine artery Doppler in nulliparous women. Am J Obstet Gynecol 2010;203:383.e1-8.

35. Giguère $Y$, Charland $M$, Bujold $E$, Bernard $N$, Grenier $S$, Rousseau $F$, et al. Combining biochemical and ultrasonographic markers in predicting preeclampsia: a systematic review. Clin Chem 2010;56:361-75. 